\title{
Economic and Social Effects of the Impact of Direct and Coupled Payments on the Development of the Agricultural Sector in Bulgaria
}

\author{
Assoc. Prof. PhD Gergana Slavova \\ University of Economics - Varna \\ ggss@ue-varna.bg
}

\begin{abstract}
The European programs, the direct and coupled payments for assistance and funding of the agricultural sector are part of the policy of the European Union aiming to create an opportunity for employment and active participation of the people from rural areas and to provide them with options for earning a sustainable income in these poorly urbanized locations. The direct payments form a part of the Common Agricultural Policy of the European Union and can be divided into several main types: Single Area Payment Scheme (SAPS), Redistributive Payments and Small Farmers Scheme intended to support small farms with a view to increasing the competitiveness in the field of smallscale agriculture. The purpose of this article is to analyze the economic and the social effects of the direct payments developmental impact during the first and the second programming periods. In order to achieve the present goal, an inquiry has been conducted together with a few in-depth interviews with small farmers who receive financial support in this way. The article contains the results of the inquiry involving leaseholders and farmers, conducted in North-East Bulgaria.
\end{abstract}

Keywords: agricultural sector, direct payments, rural areas, economic development, social effects.

JEL Code: O13, Q13, Q14; doi:10.36997/IJUSV-ESS/2019.8.2.148

\section{Въведение}

Общата селскостопанска политика (ОСП) на Европейския съюз е една от най-старите политики на съюза и е насочена към селското стопанство на страните членки в ЕС. Основната цел на тази политика е да подпомага доходността на селските стопани в съюза и едновременно с това на европейските граждани да се осигури качествена, безопасна, достъпна и питателна храна. Общата селскостопанска политика има водеща роля в прехода към по-устойчиво селско стопанство на ЕС. Тя насърчава целенасочено и системно развитието на селското стопанство на територията на ЕС и подпомага земеделските стопани, както и жизнено способността на техните земеделски стопанства и развитието на аграрна дейност в тях.

\section{1. Общата селскостопанска политика на ЕС и директните плащания, като част} от нея

Над $50 \%$ от населението на ЕС живее в селските райони, а над $82 \%$ от територията на съюза попада в тези райони, поради това е необходимо и ЕС заделя средства за стимулиране и развитие на инфраструктурата на тези райони, както и създаване на условия и дейности, като занаяти, селски туризъм, развитие на нетрадиционни дейности, които да запазят трудоспособно население в селата и да създадат условия за запазване на местните жители, обичаи и ценности. Общата селскостопанска политика обединява 28 страни, членки на ЕС в своите усилия да създаде по-добри условия за развитие на селските райони и аграрните и неземеделски дейности в тях. Основните цели на Общата селскостопанска политика са (Association of Grain Producers in Bulgaria, 2018):

Да се увеличи селскостопанската производителност, чрез развитие на техническия прогрес и осигури рационално развитие на селскостопанското производство и оптимално използване на производствените фактори и по-специално на работната сила.

Да се осигури нормален жизнен стандарт за хората занимаващи се със селско стопански дейности, чрез увеличаване на техните индивидуални доходи получавани от аграрни дейности и неземеделски дейности в селските райони на съюза. 
Да се гарантира снабдяването и да се стабилизират пазарите в селските райони и да се гарантира, че произведените и доставените аграрни продукти, достигат до потребителите на приемливи цени (European Parliament, 2019).

Към конкретните цели на ОСП, съществуват и други цели, посочени в различни разпоредби на ЕС, приложими към всички политики и действия на Съюза. Към тях се отнасят следните важни направления: насьрчаване на висока степен на заетост в селските райони, опазване на околната среда с цел насърчаване на устойчиво развитие, оказване защита на потребителите, създаване на условия за хуманно отношение към животните, опазване на общественото здраве в селските райони и икономическо, социално и териториално сближаване на селските райони и хората живеещи в тях в цялата Европейска общност. В пряка връзка с отварянето и глобализацията на пазарите се определят принципите на общата търговска политика, приложими към търговията със селскостопански продукти. Реално общата селскостопанска политика създава условия и възможности, чрез който всички селски райони на територията на европейския съюз да се развиват много поцеленасочено, комплексно, ангажирано и всеобхватно. България не прави изключение, като страна членка, а напротив още през 1999 г. с приемане на план 2000 за разширяване на ЕС в България се разработва Национален план за развитие на земеделието и селските райони, който обхваща периода 2000-2006 г., на база на него малко по-късно се подписва многогодишно финансово споразумение за пред присъединителна програма за подпомагане развитието на селското стопанство- САПАРД. Програмата е една и съща за всички присъединяващи се страни от централна и източна Европа към ЕС. Тя е с продължителност от седем години и обхваща периода 2000-2006 г. Сумата за финансиране развитието на селските райони и аграрния сектор за целия период е 444748370 евро (Association of Grain Producers in Bulgaria, 2018), а общия бюджет на цялата програма, включващ и националното финансиране, възлиза на 592961125 евро за целия пред присъединителен период. След 2007 г. страната ни като член на EC, въвежда директни плащания на площ (Ivanov, B., Popov, R., 2012) и Програма за развитие на селските райони, която до момента е минала почти през два програмни периода 2007-2013 и 2014-2020 г. На база на директните плащания на площ, България въвежда схема за единно плащане на площ, известна с абривиатюрата- СЕПП. Финансовите средства определени за нашата страна за първи програмен период по СЕПП са 4,8 млрд. лв. Като средното плащане за България е 232 евро/ха при средно за ЕС-267/ха (Association of Grain Producers in Bulgaria, 2018). На следващата фиг. 1 е представена схема на единно плащане на площ в хиляди лева за пьрви програмен период, от която се вижда, че за целия програмен период на прилагане на схемата на единно плащане се характеризира с последователно увеличение нивата на заплащане и висок темп на усвояемост на средствата, който за 2013 г. са над 99\% от определения за страната финансов ресурс (фигура 1). Броят на земеделските стопани, подпомогнати по СЕПП е сравнително равномерен през анализирания период, като най-ниска стойност има през кампания 2007 - 78596 фермера, а най-много са заявителите, получили подпомагане през кампания 2010 -91734 (Ministry of Agriculture, Forestry and Food, 2019).

През последните години директните плащания представляват основна защитна мрежа (Bečvářová, J. 2011) за българските земеделски стопани. Така например през 2014 г. около 90 490 български земеделски стопанства получават 578 милиона евро под формата на директни плащания, а през 2015 г. ЕС изразходва над 30 милиона евро за пазарни мерки в България, насочени най-вече към лозаро-винарския сектор, но и към други сектори, например на плодовете и зеленчуците (Association of Grain Producers in Bulgaria, 2018). През пьрви програмен период в страната са подпомагани основно схеми за сектор-,краве мляко”, сектор „овце и кози”, сектор „плодове и зеленчуци” с превес са били също подсектори „ягоди и малини, предназначени за преработка”, подпомагани са също и , енергийни култури”. 


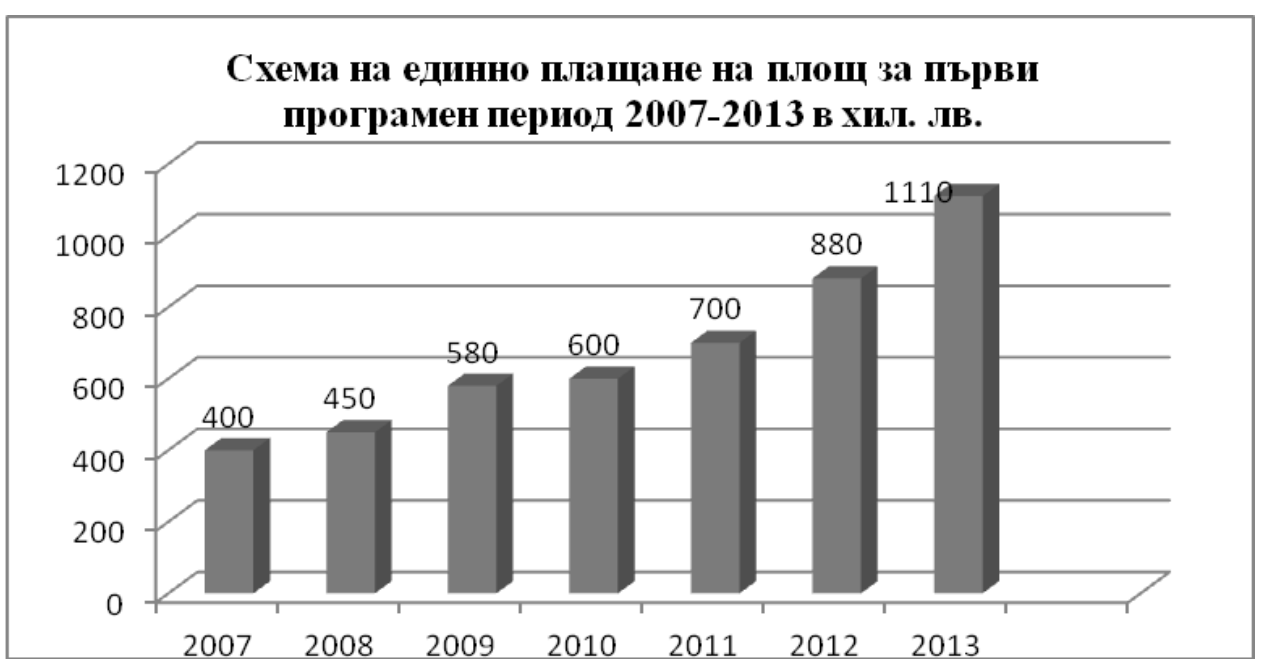

Фиг. 1 Схема на единно плащане на площ за първи програмен период 2007-2013 в хил. лв.

За директно подпомагане за втори програмен период средствата са представени на следващата фигура 2. От нея и от фигура първа можем да заключим, че средното плащане за периода е много по-високо спрямо първи програмен период. Средно за пьрви програмен период земеделските стопани за периода са получили 674 хил лв., а за втори 782 хил. евро. Не само стойността, но и паричната единица е друга, което показва по-висок ръст на финансово подпомагане от страна на ЕС за страната ни. Освен всичко казано до тук е важно да отбележим, че средното подпомагане за страната ни през втори програмен период се повишава до около 235 евро на ха (Association of Grain Producers in Bulgaria, 2018). През новия програмен период 2021-2027 г., на ОСП, няма да се наблюдава намаление на средствата за директни плащания за България, дори заради така наречената конвергенция или външно сближаване ще има леко увеличение, според министьра на Земеделието в страната ни (Minister of Agriculture, Food and Forests, 2019 ). От фигура втора се вижда, че последните четири анализирани години от 2017 до 2020, размера на изплатените средства подиректни плащания е най-висок и това е една от причините хората, който ги получават да бъдат уверени, че през новия програмен период 2021-2027 отново ще кандидатстват за подпомагане по тази линия.

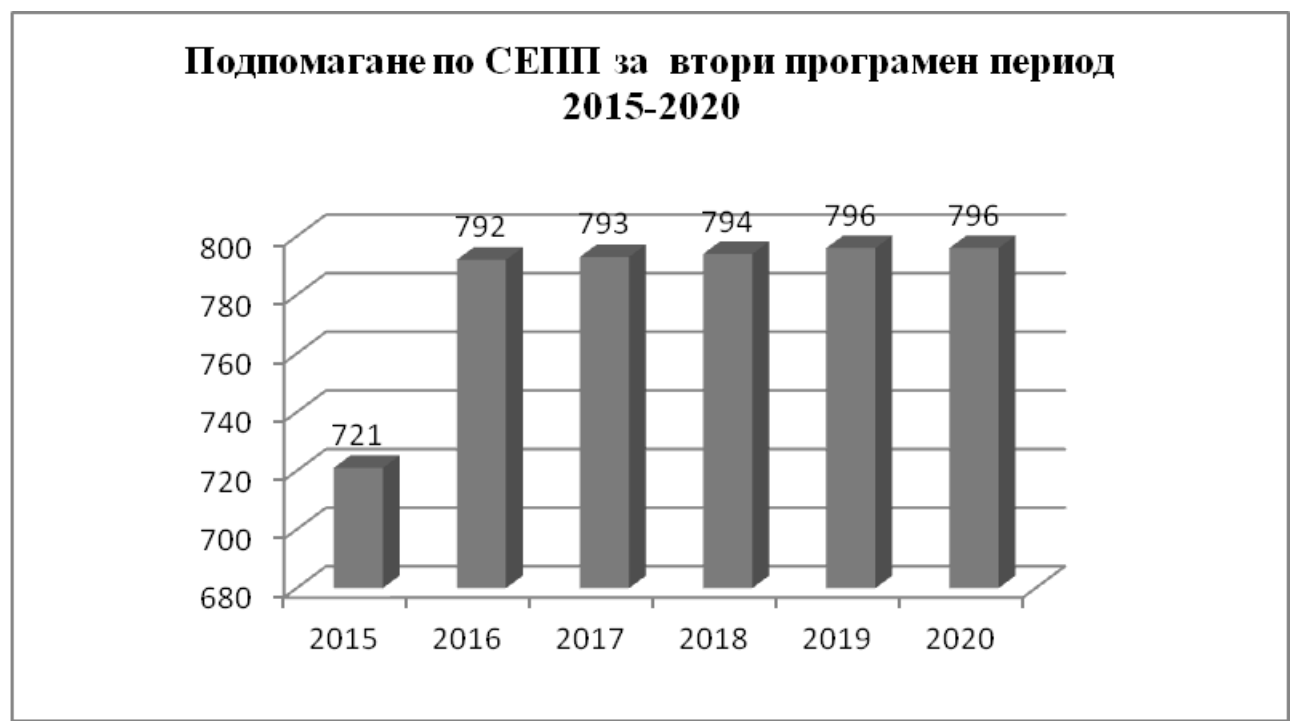

фиг. 2 Схема на единно плащане на площ за втори програмен период 2015-2020 в хил. евро 
По данни на доклада на Центъра за изследване на демокрацията цели три четвърти от директните плащания за обработваеми земи са получени от 3700 физически и юридически лица, но те представляват реално 100 свързани лица (Ingilizova, St., 2018). Според Безлов концентрацията на субсидии в земеделието води дори до някой криминални практики (Ivanov, B., Popov, R., 2012). Той припомни, че за 2018 година общо от еврофондовете България получава близо 4,2 млрд. лева. За селското стопанство те са 2,91 млрд. лева, от които 2.64 млрд. лева са от еврофондове. Приемането на таван за субсидиите от 300 хил. евро през 2014 година според икономистите е довело до раздробяване на стопанствата в България (Ingilizova, St., 2018). По подобен начин стои въпроса и в някой други европейски държави, но далеч не във всички, защото в повечето от тях коперативите се запазиха и при промяната на плановата икономика с пазарна раздробяване на площите не настьпи. (Review of Available, 2010). Бюджетът за директните плащания за България през следващия програмен период след 2020 г. няма да бъде намален с 0,7\%, каквито бяха очакванията на земеделците, а дори ще се увеличи с около 250 млн. евро. Това е официална информация от бившия министър на земеделието Румен Порожанов на дискусия на „Национален земеделски форум - Общата селскостопанска политика след 2020 г.“, домакин на която бе Националната асоциация на зърнопроизводителите ( Bocheva, N., 2018). Директните плащания за България се планира да бъдат 5,6 млрд. евро при около 5,35 млрд. евро през новия програмен период (Ingilizova, St., 2018).

\section{2. Икономически и социални ефекти от директните плащания в България}

За да установим, дали реално земеделските производители в България и в частност в Североизточната част на страната ни са доволни от получените плащания, осъществихме 17 интервюта със земеделски стопани от района. Много интересни са икономическите и социалните ефекти, отчетени като резултати до които достигнахме в следствие на проведените интервюта:

\section{Икономически ефекти:}

$>80 \%$ от интервюираните земеделски стопани считат, че системата за единно плащане на площ е много добре обмислена и функционира изрядно, което води до повисоки доходи на работещите в аграрния сектор. Според интервюираните финансирането по схемите за обвързани плащания, не винаги се базира на ясни критерии и правилата и те твърде често се променят.

$78 \%$ считат, че при директните плащания няма забавяния и до голяма степен се спазва индикативния график на МЗХ, което позволява да се направи по-добра икономическа преценка и плановост в производствения процес.

$>$ Според 55\% от интервюираните земеделски стопани най-големият проблем е многократното посещение на службите по земеделие по райони, тъй като от икономическа гледна точка, това е свързано с разходи и загуба на време.

$>$ Според 75\% най-голям процент от времето отделяно за да се получат директни плащания се губи при заверка на регистрационна карта, очертаване на парцелите и заявяване за подпомагане по конкретните схеми за директно и обвързано подпомагане.

$>$ Над 98\% от интервюираните отново биха кандидатствали и през трети програмен период за подпомагане по СЕЕП.

$>$ За обвързано подпомагане биха кандидатствали по-малко 65\% от интервюираните.

$>90 \%$ от интервюирани земеделски производители считат, че ако намалеят отпуснатите финансови средства под формата на директни плащания, земеделските стопани няма да обеднеят много или да фалират, тъй, като голяма част от ангажираните в земеделието не са в него само заради субсидиите, а поради желание да се развиват в областта на аграрния сектор. Тези които са в сектора заради субсидиите, колкото и малко да са икономически, пазарът ще стане безинтересен за тях и ще се насочат към други сфери на дейност, например търговия, строителство или индустриално производство. 
$>$ Според 50\% от интервюираните премахването на плащанията ще е огромен натиск за подобряване на ефективността, за гледане на култури с висока добавена стойност, т.е преработени земеделски продукти и произведени крайни продукти, като лютеници, сладка, мармалади и други консерви или биохрани и т.н.

\section{Социални ефекти:}

$>$ Според $45 \%$ се отделя много време и за заявяване на правно основание, многократни сбирки за сключване на споразумения за площите и други служебни срещи свързани с уреждане на преки въпроси относно директните плащания и обвързаното подпомагане.

> Почти всички 99\% от интервюираните земеделски производители считат, че потребителите винаги ще са готови да плащат повече за пресни местни и традиционни храни, затова се ориентират в тяхното производство, което осигурява социални контакти и добра социална среда за възраждане на българските традиции.

$>$ Според 85\% ако се насочат повече финансови средства от директните плащания по посока на екологичните плащания, земеделските стопани очакват по-голям екологичен и социален ефект, който ще доведе до бързо увеличаване на площите с гори и дървесни видове и храсти, което от своя страна ще доведе по-добри социални условия за съществуване на хората в дадения район;

$>$ Според 78\% от интервюираните земеделски производители получаващи до момента директни плащания, цените на хранителните суровини не следва да се увеличат, тъй като по-големите, отворени пазари предполагат по-голяма конкуренция, а при нея се появяват повече производители и съответно по-балансирани пазарни цени.

$>$ Според тях, излизане на южните пазари означава, че и нашите земеделски производители ще могат да реализират своите земеделски храни на юг и $85 \%$ считат това , като добра възможност за нова реализация на българска земеделска продукция при нови социални условия.

$>95 \%$ от тях обаче считат, че те са малки и поради това трябва да обединят усилията си в сформиране на производствени съюзи по отделни отглеждани култури, за да могат колективно да защитават своите права.Това ще създаде възможност те да бъдат социално поорганизирани и обидинение.

$>$ Според 89 \% от интервюираните земеделски производители, спирането на субсидиите ще отстрани от отрасъла нереалните пазарни играчи, които са в него заради получаване на безвъзмездни директни плащания. Това ще има за тях, както социален така и икономически ефект не само за тях, но и за всички в този сектор;

$>$ Според едно друго реализирано проучване на института за пазарна икономика (Valkanov, N., 2013), проблемите са от съвсем друго естество. Основните проблеми на земеделските производители според ИПИ са свързани най-вече с разликата в размера на получаваните субсидии в България и в други страни членки на $\mathrm{EC}$, както и раздробената собственост върху земята.

Според общата селскостопанска политика, а и според нас бъдещето пред земеделските стопани е в създаването на къси вериги от производителя до потребителя. В следващата таблица могат да се видят конкретните стойности на директните и кръстосани плащания за 2018 г.

Таблица 1. Видове директни и преразпределителни плащания, и стойност по тях за 2018 г.

\begin{tabular}{|c|l|c|}
\hline $\mathbf{N}$ & \multicolumn{1}{|c|}{ Видове директни и крьстосани плащания } & Лева на хектар \\
\hline 1. & Схема за единно плащане на площ & 195,73 \\
\hline 2. & Схема за обвързано подпомагане за протеинови култури & 135,64 \\
\hline 3. & Зелени директни плащания & 122,84 \\
\hline 4. & Схема за пре разпределително плащане & 137,55 \\
\hline
\end{tabular}


Най-голям дял от финансовите средства са насочени към схемата за обвързано подпомагане при оранжерийните зеленчуци, следвани от схемата за обвързано подпомагане при плодовете. Най-ниска е стойността на схемата за плащане за селскостопански практики, които са благоприятни за климата и околната среда, така наречените-зелени директни плащания. Въпреки, че през новия програмен период 2021-2027, те ще бъдат приоритетни. Определено можем да обобщим, че директните и обвързани плащания през годините нарастват, а с това и удовлетвореността на техните ползватели. Голям процент над $89 \%$ считат, че спирането на субсидиите само ще отстрани нереалните земеделски стопани от пазара. Още по-голям процент от тях твърдят, че ще продължат да кандидатстват за директни или обвързани подпомагания. Според тях единствените притеснения на регионално ниво са многократните посещения на службите по земеделие по райони. Висок процент от интервюираните отчитат, че губят много време при заверка на регистрационни карти и очертаване на парцелите за заявено подпомагане по конкретните схеми за директно и обвързано подпомагане. На национално ниво се изтьква главно проблема с по-ниските субсидии спрямо тези на други силно развити европейски държави. Това е реален факт, но за него има обективни причини и ние считаме, че този проблем не може да бъде разрешен вследствие настоящото изследване.

Отличителен момент и едно от най-големите постижения,произтекли от присъединяването на страната ни в ЕС и прилагането на ОСП,е повишаването на размера на стопанисваната земеделска земя. След последното преброяване в страната е установено, че:

Специализирани стопанства в аграрния сектор са 73, 5\%; Смесени стопанства са $26,2 \%$, като относителен дял от структурата на всички земеделски стопанства в страната и некласифицираните стопанства са $0,3 \%$, като относителен дял от структурата на всички стопанства в страната. ${ }^{1}$ В следствие приобщаването на България към ЕС и Участието и към ОПРСР и всички други помощни лостове на ОСП, като директни плащания и други видове финансова подкрепа спрямо института за аграрна икономика към селскостопанска академия доходността на българските фермери расте, а едновременно с това намаляват реално заетите в сектора, в резултат от модернизиране и техническо обновление на сектора по ОПРСР. „Стойността на факторния доход показва непрекъснат ръст след 2007 г., като през 2016 г. достига 7 хил.евро на 1 ГРЕ. Земеделието има сериозно място при заетостта в селските райони, като около $1 / 3$ от заетите са именно в този отрасъл. В селските райони,създаваната добавена стойност на 1 зает в земеделието се равнява на около 3,3 хил.евро, докато общо добавената стойност на зает в тези райони е 8,6 хил.евро." (Ivanov, B., Popov, R., Malamova, N., Mitova, D., Sokolova, E., Totev, D., Dimitrova, D., Stoychev, V., Djodzhova, A., Gorcheva, K. (2017) (Иванов, Б. и 2017). Тези данни, още веднъж потвърждават резултатите от нашето направено изследване, а имено, че директните плащания превличат участие на земеделските стопани в сектора, но далеч не са единствената причина те да бъдат земеделски стопани. Аграрния сектор е бил, е и ще бъде основен сектор в страната ни, а фермерите и земеделските стопани ще развиват успешно своята дейност с подкрепата на европейския съюз, независимо дали под формата на директни плащания, обвързано подпомагане или финансиране по някоя от мерките на оперативна програма за развитие на селските райони.

\section{Заключение}

Ползите които могат да бъдат посочени от направеното изследване е, че голяма част от анкетираните земеделски производители (95\% от тях) считат, че те са малки и поради това трябва да обединят усилията си в сформиране на производствени съюзи по отделни отглеждани култури, за да могат колективно да защитават своите права. Това определено е

\footnotetext{
1 Изследване на структурата на земеделските стопанства през 2016 година- НСИ, www.nsi.bg
} 
важна стъпка напред към промяна на начина на мислене и не само, най-вече на социалните взаимоотношения и икономическите последствия след това. Земеделските стопани в анализирания регион на база направените интервюта са готови да посрещнат измененията в общата селско стопанска политика на европейския съюз, тъй като според повечето от тях (85\%), ако се насочат повече финансови средства от директните плащания по посока на екологичните плащания, те очакват по-голям екологичен ефект, който ще доведе до бързо увеличаване на площите с гори и дървесни видове и храсти. Осъщественото изследване показва, че земеделските стопани са удовлетворени, като цяло от ОСП, а в частност от директните и обвързани плащания и биха продължили уверено своята дейност, както с тях, така и без тях, тъй като от секторьт ще излязат единствено нереалните земеделски стопани, ако плащанията бъдат спрени.

\section{References}

1. Bocheva, N., (2018), Budget for direct coverage for Bulgaria will be increased, Supply of money reduction for rural areas will be compensated with national funds, https://www.investor.bg/evroproekti/ - Economic Information Specialized Site, September 12, 2018 ,

2. Valkanov, N., (2013). What are the problems of farmers? - https://ime.bg/en/articles, 05/17/2013

3. Ivanov, B., Popov, R., (2012) "Bulgarian Agriculture and the Results of Proposed Changes in the CAP", Sofia, p.15

4. Ivanov, B., Popov, R., Malamova, N., Mitova, D., Sokolova, E., Totev, D., Dimitrova, D., Stoychev, V., Djodzhova, A., Gorcheva, K. (2017) .- Synthesized Carefully, 10 years CAP in Bulgaria, Agricultural Academy, Institute of Agrarian Economics

5. Ingilizova, St., (2018), Three-quarters of direct coverage in agriculture targeted 100 people in agriculture, https://fakti.bg/bulgaria/, September 17, 2018

6. Bečvářová, J. (2011), "Economic and Regional Consequences of Direct Payments under the Current CAP Philosophy”, Acta Universitatis Agriculturae Et Silviculturae Mendelianae Brunensis, Volume LIX Number 4, 2011

7. Review of Available Literature on Direct Payments in NMS CC and PCC Synthesis; March 2010; AgriPolicy Enlargement Network for Agripolicy Analysis

8. https://ec.europa.eu/info/sites/- European, main website for the CAP and Member States' direct spending, September 2019

9. Association of Grain Producers in Bulgaria, (2018), Focus CAP, ed. of the Bulgarian Farmers Association, co-financed by the European Commission, 2018, p.27

10. https://agri.bg/novini/- No drop in direct payments during the new programming period interview with the Minister of Agriculture, Food and Forests, September, 2019.

11. Direct payments from the common agricultural policy in Bulgaria in the period 2015-2020, Ministry of Agriculture, Forestry and Food, http://www.mzh.government.bg/, September, 2019

12. http://www.europarl.europa.eu/- CAP of the EU portal to the European Parliament, 2019 